\title{
Xirú: barro, comunidade e identidade em uma narrativa fronteiriça
}

\author{
Xirú: barro, comunidad e identidad en una narrativa fronteriza \\ Xirú: clay, comunity and identity in a borderline narrative
}

\begin{abstract}
Resumo
O texto realiza uma análise da obra fronteiriça Xirú (2012), do escritor paraguaio Damián Cabrera. Esta põe em questão a denominação coletiva xiru, termo que apesar de significar, na sua origem guarani, amigo, companheiro é utilizado pelos brasileiros para se referir de maneira pejorativa aos paraguaios. Há vários choques entre os sentidos relativos a termos identitários, especialmente, ao termo xiru, assim como verifica-se uma complexidade referente a outros elementos nacionais como o território e a língua, no interior da obra. A partir destes aspectos e considerando o barro e a forma fragmentária como elementos produtivos, verifica-se neste livro fronteiriço o registro de uma comunidade alternativa à comunidade nacional.
\end{abstract}

Palavra-chaves: barro, comunidade, identidade, narrativa fronteiriça

\section{Resumen}

El texto realiza un analisis de la obra fronteriza Xirú (2012), del escritor paraguayo Damián Cabrera. Esta pone en cuestión la denominación xiru, término que apesar de significar, en su origen guarani, amigo, compañero es utilizado por los brasileros para se referir de modo despectivo a los paraguayos. Hay vários choques entre los sentidos relativos a términos identitarios, especialmente, al término xiru, así como se verifica una complejidad referente a otros elementos nacionales como el território y la lengua, en el interior de la obra. A partir de estos aspectos y considerando el barro y la forma fragmentária como elementos productivos, se verifica en este libro fronterizo el registro de una comunidad alternativa a la comunidad nacional.

Palabras clave: barro, comunidad, identidad, narrativa fronteriza

\begin{abstract}
The text analizes the borderline work Xirú (2012), by the Paraguayan writer Damián Cabrera. It questions the denomination xiru, term that means friend o mate, in its gurarani's origin, although it is used by Brazilian to refer to Paraguayn in a pejorative way. There are several shocks between the relative meanings of identity terms, especially, to the term xiru, as it is verified a complexity referring to other national elements with territory and language, in this work. Given these aspects and considering the clay and the fragmentary way as productive elements, it is verified in this borderline book the register of an alternative community to the national community.
\end{abstract}

Keywords: clay, community, identity, borderline narrative

\footnotetext{
${ }^{1}$ Doutora em literatura, Universidade Federal da Integração Latino-americana - UNILA, Foz do Iguaçu, Paraná, Brasil; deboracota.lit@gmail.com. Trabalho apresentado no I Seminário Latino-americano de Estudos em Cultura - SEMLACult, Foz do Iguaçu/PR, Brasil, 2017.
} 
Um barro de coloração vermelha, chamado também de terra roxa, adentra a região da Tríplice Fronteira e reúne Brasil, Paraguai e Argentina: inunda os caminhos indígenas, alimenta as plantações do agronegócio, suja os pés dos vendedores e as malas dos turistas. Este mesmo barro estampa as capas dos livros Xirú (2012), do escritor paraguaio Damián Cabrera; Roça Barroca (2011), que reúne as traduções de mitos guaranis, da brasileira Josely Viana Baptista; além de dar título à produção cinematográfica brasileira Terra Vermelha (2008), de Marcos Bechis. Estende-se pelas mãos de ceramistas como as da artista Maria Cheung, radicada em Foz do Iguaçu, e enlaça as atividades de ceramista e poeta de criadoras importantes como Josefina Plá (1903 Espanha-1999 Paraguai). Além disso, a 300 km de Foz do Iguaçu, a capital do Paraguai, Assunção, detém o imponente Museo del Barro que abriga uma relevante coleção de cerâmica popular e uma coleção de cerâmica arqueológica da cultura guarani.

A recorrente presença deste elemento na região tem chamado a atenção para o barro como um elemento produtivo e agregador de várias artes; denunciador de problemas sociais latentes como os da distribuição de terras e do agronegócio; possivelmente, como demarcador de uma estética; e, essencialmente, definidor da arte da cerâmica.

Por outro lado, o barro é um elemento mítico que sempre remete ao primordial, ao original: o livro bíblico Gênesis, diz que Deus modelou o homem com a argila do solo, insuflou em suas narinas um hálito de vida e o homem se tornou um ser vivente. Seja dentro da tradição cristã ou não, a terra é um elemento por vezes sagrado, de definição identitária e cultural e, por isso, sempre figurou como elemento de disputa, (de defesa ou de dominação), de tensões e conflitos.

Em tempos de globalização, de intensos movimentos migratórios, o que nos fala acerca das discussões em torno das concepções de comunidade e identidade cultural na América Latina este elemento simbólico e de cunho fundacional? Um pequeno livro terracota, fronteiriço e cheio de pó nos serve aqui para pensar as desestabilizações identitárias e a emergência de novas comunidades na produção literária contemporânea.

\section{Xirú}

Em 2012, é publicado pela Ediciones de la Ura, uma editora independente do Paraguai, interessada em projetos experimentais e em práticas culturais, Xirú, livro do jovem escritor paraguaio Damián Cabrera. O autor é conhecido na cena cultural daquele país por atividades de gestão cultural, como oficinas de escrita criativa e, em especial, pela edição e 
compilação, junto a Olga Bertinat, da Revista/Espacio de expresión cultural El Tereré, entre 2006 y 2012. Damián Cabrera passou toda sua infância e juventude na região do Alto Paraná, a região fronteiriça na qual está ambientada Xirú e, atualmente, cursa mestrado na Universidade de São Paulo.

O livro teve um capítulo publicado na polêmica coletânea: Los chongos de Roa Bastos: narrativa paraguaia contemporânea (Argentina, 2011), lida como provocadora a autores anteriores, e recebeu o Prêmio Roque Gaona, prêmio de melhor novela paraguaia de 2012, outorgado pela Sociedade de Escritores do Paraguai e normalmente dado a escritores com um maior caminho trilhado na área literária.

A denominação brasileira "xirú” provém da palavra guarani Chei'ru que significa meu amigo, meu companheiro. Porém, dependendo de quem e a situação em que se utiliza, ela pode carregar um tom depreciativo, negativo, muito comum entre os brasileiros da região fronteiriça ao se referirem aos paraguaios, ou mesmo aos brasiguaios, (brasileiros que vivem no Paraguai) quando encontram-se ou retornam ao Brasil. Damián Cabrera intitula de "sentido deslocado", seu texto que fala do livro chamando a atenção para a tensão subjacente ao uso do termo pelos brasileiros, mas também para outro conflito fundamental que marca a região: o da terra.

Xirú é lançado no ano do conhecido massacre de Curuguaty (2012) que levou ao polêmico e questionável juízo político e destituição do presidente Fernando Lugo. A invasão policial no assentamento Marina Kue foi um dos maiores conflitos por terra naquele país, nos últimos tempos. O evento, ainda que imediatamente posterior ao livro, se antepõe na narrativa já que sua escrita está tocada pelas mesmas questões sociais que caracterizam o incidente.

Trata-se de uma narrativa fragmentária, com uma complexidade envolta em descontinuidades e elipses. Além disso, é fronteiriça não apenas por ter como pano de fundo este lugar geográfico, mas por tratar-se como afirmam Laura Kornfeld e Rocco Carbone (2014), “de um texto literário lingüísticamente fronterizo, narrativamente fronterizo”. Está escrito nos três idiomas da fronteira (espanhol, guarani e português): "Y por eso decimos triborder: triple grafía, triple lengua, triplefrontera. Triplicidades (...) que arman una región hecha de pedazos, de fragmentos; de esos mismos fragmentos que confeccionan el texto de Cabrera.”, explicam Kornfeld e Carbone (2014, p. 1).

A narrativa recolhe várias vozes, que materializam no texto o contato linguístico destes idiomas em situação de oralidade e, ao mesmo tempo, dão complexidades às identidades: a dos adolescentes paraguaios César, Gabriel, Nelson e Miguel; a do colono Silvio que serve ao seu patrão brasiguaio, Seu Washington em conflito com os sem-terra; ou 
ainda a da brasiguaia Maria, que apesar de brasileira vivendo no Paraguai, representa papel totalmente distinto do Seu Washington, em termos sociais, o que aponta para a não homogeneidade da situação social dos brasileiros no Paraguai. Assim sendo, dá a conhecer a ineficiência de definições identitárias envoltas em termos como paraguaio, brasiguaio, brasileiro e xirú. Assim como as línguas, se chocam as várias matizes de sentidos que subjazem estas denominações, especialmente, as que correspondem à figura do xirú.

\section{Barro}

A capa do livro terracota possui a mesma coloração do barro vermelho que abunda no Paraguai e região. Conforme Lia Colombino (2013): "La tapa fue creación de Ana Ayala y resulta de la esquematización de un sojal. El color de la tapa trató de parecerse a ese color de la tierra que tienen en Minga Guazu bajo sus pies y que tiñe todo el libro desde su comienzo.” Já no interior do livro, o barro ganha contornos poéticos, como na página 70: "El cielo está gris. Un viento fuerte azota las copas más altas de los árboles, tensiona sus troncos. Un paredón de polvo se levanta y los embiste. El cielo está rojo.” (CABRERA, 2012) O pó, a coloração vermelha, a terra e suas modelações servem para definir poeticamente a paisagem mas também para tratar dos corpos e do territórios. Já na entrada do livro recebemos um convite à experimentação de um espaço com o corpo, um convite que através do barro demarca este território xiru:

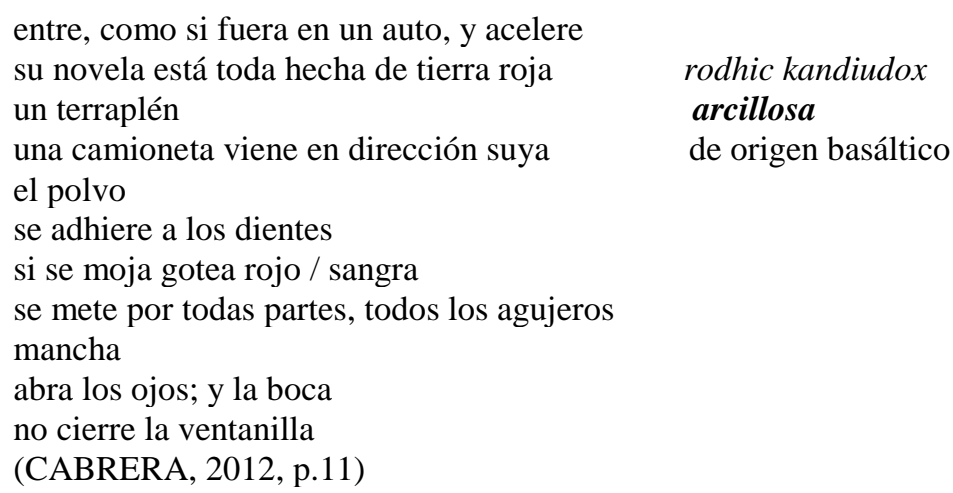

$\mathrm{O}$ fragmento, primeiro escrito em letra diferente e menor do que a dos demais, aponta para a necessidade de experimentação da terra, do barro com o corpo, para a necessidade de envolver-se com a terra vermelha, o barro ou o pó para se adentrar ao território Xirú. Somos convidados a entrar no livro como se entrássemos em um território a que só é possível conhecermos nesta relação estreita com a terra, se deixarmos nossos corpos serem tomados 
por ela. Trata-se de um imaginário acerca da relação entre corpo e território ou território como corpo que prevê, conforme Josefina Ludmer, movimento e não fixação:

Los cuerpos son anexos al territorio; desde esta perspectiva, un territorio es una organización del espacio por donde se desplazan cuerpos, una intersección de cuerpos en movimiento: el conjunto de movimientos de cuerpos que tienen lugar en su interior y los movimientos de desterritorialización que lo atraviesan. Y eso puede verse a través de las ficciones. (LUDMER, 2012, p. 123)

Neste sentido, a obra se propõe como território a ser percorrido pelos corpos dos leitores, mas também como território de corpos em movimento, conjunto específico, inclusive, de movimento de corpos relacionados à dinâmica fronteiriça do lugar. Como um "terraplén", um aterro, é criado, ou seja, não se funda em algo natural e sim no movediço, no que foi transformado ou está em transformação. O barro vermelho de Xirú, o mesmo de Roça barroca e Terra vermelha, é um barro transnacional, o barro da fronteira Brasil-Paraguai. Resta saber o que funda este barro em movimento, esse barro pó, de que está feito o livro. Que comunidade se estabelece no movimento deste território?

\section{Comunidade xirú}

As páginas 75 e 76 de Xirú correspondem ao que podemos chamar de capítulo 21, ou fragmento 21. Nelas encontram-se importantes diálogos, também fragmentados, em que o tom depreciativo e preconceituoso de brasileiros para com os paraguaios são narrados. Eis um exemplo:

- O Xirú é preguiçoso. É só olhar pro Seu Martínez. Ele acorda às cinco da manhã, toma o seu chimarrão, vai pra chácara um pouquinho, volta e toma tereré embaixo da árvore; ele fica aí umas duas horas com o olhar perdido que nem esses monges, ou sei lá que diacho. Não quer trabalhar. Pra que quer terra? (CABRERA, 2012, p. 75-76)

O termo xirú propõe uma coletividade. Poderia significar um tipo social, mas é constituído a partir da negatividade, uma negatividade que, antes de mais nada, parece negar a nacionalidade ou problematizar a origem e o pertencimento à nação. A força do termo encontra-se, no fragmento acima, justamente, na tentativa de criação de definição do ser xirú, de definição de sua identidade, na criação de "substâncias" em comum que justificariam a perspectiva coletiva, para pensar desde as preocupações de Roberto Espósito (2012) quem se preocupa com o fracasso que é inerente a comunidade pensada através de essencialismos e 
substâncias. Mas, o fragmento é representativo apenas de um microcosmo que habita a narrativa: a dos colonos brasileiros. Para além deles, como se viu, temos os próprios paraguaios e brasiguaios que vivem no Paraguai em situação diversa da dos colonos. Se xirú, a designação dos brasileiros aos paraguaios força uma identidade, Xirú, o livro de Damián Cabrera, propõe que a coletividade e/ou a comunidade inerente ao termo xirú seja apenas pensada pela via da heterogeneidade e não pela homogeneidade tradicional das comunidades nacionais.

Produções como Xirú, não propõem processos harmônicos transculturadores e sim são resultantes de encontros culturais tensos, conflitantes, como a dinâmica das relações entre brasileiros e paraguaios abordada no livro. Este traz a configuração de uma comunidade que se constitui a partir do olhar do Outro que, em contato, não se hibridiza ou não se coloca em situação de transculturação, apesar do contexto de convivência. Xirú é um apelido dado pelos brasileiros, quase um gentílico que substitui o tradicional gentílico "paraguaio". Um termo polissêmico. Há que lembrar que a origem guarani do termo reforça o tom pejorativo já que o índio, também no Brasil, é considerado um grupo social etnocentricamente de menor prestígio.

Sobre a presença do Outro na configuração da comunidade, Peter Pal Pelbart explica que na comunidade já não se trata de uma relação do Mesmo com o Mesmo, mas de uma relação na qual intervém o Outro, e ele é sempre irredutível, em dissimetria, ele introduz a dissimetria, impedindo que todos se reabsorvam em uma totalidade ampliada. (PELBART, p. 6). O Outro atua diretamente na comunidade e instaura a dissimetria, o movimento. A comunidade xirú é impossível sem o Outro, o que está em desacordo, o que não entra em fusão. Um Outro do nacional, como o estrangeiro que habita o mesmo território, ou o compatriota que habita o mesmo território mas ironicamente não tem terra. Ao chamar a atenção para esta figura, Cabrera destaca uma comunidade normalmente concebida às margens da sociedade e não abrigada pela nação imaginada paraguaia, uma vez que, como considera Benedict Anderson, a nação se imagina limitada. (1983, p.25)

O que está em questão, portanto, são tensões de cunho identitárias nacionais. Xirú demonstra um menosprezo e até a xenofobia do brasileiro pelo homem tradicional paraguaio. Ainda que de maneira geral o gentílico "paraguaio" já contenha no Brasil tom depreciativo, principalmente, quando se trata de produtos eletrônicos provindos do comércio de Ciudad del Este, é o termo xirú, por sua condição impura que é o empregado. A dinâmica fronteiriça, neste caso, é sobretudo heterogênea, marcada pela complexa e tensa relação cultural que desestabiliza identidades. Em Xirú estão os xirús mas também estão os paraguaios, os 
brasiguaios, os sem-terra, os brasileiros. Cabrera subverte a substancialização (ESPÓSITO, 2012) que o termo carrega, apontando para a complexidade e não identidade que o termo alude.

Encontra-se, neste sentido, no livro um processo de identidades móveis, muito baseada no conflito entre brasileiros e paraguaios. O personagem Silvio, por exemplo, é um colono brasileiro que serve a um brasiguaio proprietário de terras no Paraguai mas, que em determinado momento, se junta aos xirús, neste caso, sem-terras, acobertando a ocupação destes últimos às terras do patrão. Já Maria e o Seu Washington são brasiguaios, ou seja, brasileiros que vivem no Paraguai, mas que se opõem já que um representa o patrão, o proprietário de terras e outro o brasileiro pobre e analfabeto que é menosprezado pelos paraguaios. Ou seja, personagens que acabam se identificando com tipos de origem nacional diferente da sua; ou personagens provenientes da mesma nacionalidade, mas que em nada se parecem. Enfim, personagens que carregam identidades irredutíveis, não fixas, provisórias.

Por outro lado, na narrativa encontram-se, em destaque, os três grupos de personagens já citados, que acenam para histórias diferentes. Apesar de aparentemente pertencerem a um mesmo lugar geográfico, são núcleos diferentes, uns mais urbanos outros mais rurais. Sem falar dos fragmentos de caráter mais intimista, como os fragmentos poéticos. Tudo está disposto em forma de fragmentos, as histórias dos três grupos de personagens se intercalam e ao mesmo tempo são intercaladas por passagens mais poéticas, em letra diferente dos demais fragmentos, como foi visto. Ao mesmo tempo não são fragmentos que necessariamente se unem para constituir um sentido, uma totalidade. $\mathrm{O}$ formato propõe, antes, uma recusa à totalização e a opção pela descontinuidade e o inacabamento dialogam com a dinâmica fronteiriça e a mobilidade das identidades.

O livro é uma constante provocação a se pensar questões em torno da comunidade já que possui como mote uma denominação coletiva, xirú, e coloca em prática um processo de esvaziamento das propriedades comuns a certas ideias de comunidades, principalmente de comunidades nacionais. Em Xirú a origem é deslocada, problemática, provisória. A condição explorada é sempre a de fronteira, a de indefinição. O xirú só existe a partir do olhar do outro. O barro vermelho e a problemática em torno da terra para a qual aponta são transnacionais. Neste sentido, todos os vínculos tradicionais imaginários de uma nação ou da comunidade nacional estão em questão: o texto é trilíngue e majoritariamente oral; o território é fronteiriço e insiste no corpo heterogêneo da cultura ali presente; e a comunidade em foco é xirú, uma comunidade provisória, dada a partir do olhar do outro, e em algum caso, uma comunidade sem terra, ou sem território. Estes são todos elementos descartados ou ainda não utilizados 
dentro do discurso nacional apontando para uma busca de uma comunidade pensada desde outras possibilidades.

\section{Referências}

ANDERSON, B. Comunidades imaginadas: reflexiones sobre el origen y la difusión del nacionalismo. Trad. Eduardo L. Suárez. México: Fondo de Cultura Econímica, 1993.

CABRERA, D. Xirú. Asunción: Ediciones de la Ura, 2012.

Xiru o la literatura del coloniaje contemporáneo. E'a. Fevereiro de 2013. Disponível em http://ea.com.py/v2/xiru-o-la-literatura-del-coloniaje-contemporaneo/ Acesso em fevereiro de 2017.

Xirú el sentido deslocado. Sures n.1, 2013. Disponível em:

https://revistas.unila.edu.br/sures/article/viewFile/7/5. Acesso em março de 2017.

COLOMBINO, L. Sobre Xirú de Damián Cabrera. Disponível em:

https://torore.wordpress.com/2013/03/08/sobre-xiru-de-damian-cabrera-lia-colombino/ Acesso em fevereiro de 2017.

ESPÓSITO, R. Communitas: origen y destino de la comunidade. Trad. Carlo Rodolfo Molinari Marotto. Buenos Aires: Amorrortu, 2012.

KORNFELD, L. CARBONE, Rocco. Triborder: Xirú. Sures, n. 4. Disponível em: https://revistas.unila.edu.br/sures/article/view/242. Acesso em fevereiro de 2017.

LUDMER, J. Imaginar el mundo como espacio. In: Aquí América Latina: una especulación. Buenos Aires: Eterna Cadencia, 2010.

PELBART, P. P. Elementos para uma Cartografia da Grupalidade. Disponível em: https://desarquivo.org/sites/default/files/pelbart_peter_elementos.pdf. Acesso em: $08 \mathrm{de}$ Março 2017. 